\title{
Regulation of nursing practice in the Region of the Americas
}

\author{
Silvia Helena De Bortoli Cassiani', Kimberly Lecorps², Luz Karina Rojas Cañaveral2, \\ Fernando A Menezes da Silva ${ }^{1}$ and James Fitzgerald ${ }^{1}$
}

Suggested citation Cassiani SHB, Lecorps K, Rojas Cañaveral LK, Da Silva FAM, Fitzgerald J. Regulation of nursing practice in the Region of the Americas. Rev Panam Salud Publica. 2020;44:e93. https://doi.org/10.26633/RPSP.2020.93

ABSTRACT Objective. To describe and analyze the current nursing regulations across countries in the Region of the Americas.

Methods. A country comparative analysis was carried out by gathering information from the ministries of health, nursing schools, councils, associations, and boards in 2018. The main categories evaluated were type of regulatory bodies, requirements for initial professional registration, and registration renewal.

Results. All countries regulate the nursing profession through a regulatory body. Competency exams for initial registration are required in the United States, Canada, and most Caribbean countries. Registration renewal is required in $54.3 \%$ of the countries. Continuing education is required for professional registration renewal in the United States, Canada, and 53\% of Caribbean countries. Labor hours are required in the United States and Canada.

Conclusion. Regulations promote and protect professional integrity. The Pan American Health Organization/ World Health Organization recommends that countries make efforts to evaluate competency and training, consider the use of competency exams for initial registration, and add continuing education as requirements for registration renewal.

Keywords Health workforce; community health nursing; legislation as topic; education, nursing, continuing; nurse's role; Americas.

A competent and well-trained workforce that is resilient, adaptive, and responsive to population needs is essential to achieve universal access to health and universal health coverage (1). Access to competent and qualified health personnel are necessary for well-functioning health systems and quality services delivery. Health professionals that are motivated, well distributed, empowered, and formally educated can deliver appropriate health services to address population needs.

In the last 10 years in the Region of the Americas, there has been an increase in the number of health professionals due to a growing number of health science education programs (1). However, insufficiency in education and practice regulations have impacted the quality of training, the relevance of academic

\footnotetext{
Pan American Health Organization/World Health Organization, Washington, D.C., United States of America $\square$ Silvia Helena De Bortoli Cassiani, cassianis@ paho.org
}

programs, and the professional practice (1). Regulation has been defined as the local and national government oversight of a professional practice to avoid the risk of harm to the public if practiced by an unprepared or incompetent person (2).

In 2017 the $29^{\text {th }}$ Pan American Sanitary Conference approved the Resolution CSP 29/10 Strategy on Human Resources for Universal Access to Health and Universal Health Coverage. The first strategic line of action: Strengthen and consolidate governance and leadership in human resources for health (HRH), requests the implementation of intersectional processes to allow for development, implementation, and evaluation of regulatory frameworks for HRH (1). This strategy emphasizes that adequate funding with specific regulations for the health sector

\footnotetext{
2 Consultant, Washington, D.C., United States of America
} 
will enable the offer of quality jobs, expansion of employment opportunities for inter-professional teams, and task sharing particularly at the first level of care.

Nurses play an integral role in achieving universal access to health and universal health coverage. To ensure that nurses are well prepared and effectively distributed, it is important that the countries provide a regulatory framework that guarantee competency, outlines scopes of practice, and promotes continued learning and professional development. The Strategic Direction for Nursing in the Region of the Americas, states that "country-specific regulation of nursing practice needs to be implemented and enforced. In some countries, the lack of regulations governing the scope of practice has led to widespread job dissatisfaction and attrition" (3).

The process of registration, renewal, competency exams, and continuing education hours required to register a nurse, ensures that qualified professionals practice ethically and legally. The registration is tracked by country or state regulatory bodies and is a fundamental element for the social guarantee of quality and patient safety. In addition, it is a mechanism that allows for evaluation of the academic, scientific, and technical competence levels of the professional (4).

The Pan American Health Organization/World Health Organization (PAHO/WHO) has called for the development of a people, family, and community centered, integrated quality health service model, a holistic approach to service delivery focused on the health needs and expectations of people and communities (5). This call to action has generated the need to consider the regulation of professional practice to ensure quality and ethics are maintained in health care delivery.

The Global strategy on human resources for health: Workforce 2030 recommends collaboration among professional councils and the government to implement effective regulations of health professionals (6). This includes keeping a registry of the health workforce, overseeing accreditation of academic programs, and implementing mechanisms to ensure continuing competences (6). This is further explained and supported by the Global strategic directions for strengthening nursing and midwifery 2016-2020 in which the objective is to educate, recruit, deploy, and retain nurses with appropriate competencies, equipped with the necessary resources and governed by professional regulation (7).

The Plan of Action on Human Resources for Universal Access to Health and Universal Health Coverage 2018-2023 encourages PAHO Member States to draft and implement regulations for professional practice that allow for optimal utilization of the competencies of health professionals, and appropriate coordination and supervision mechanisms to improve coverage and quality of care. It targets that by 2023, 19 countries in the Region of the Americas will have formal regulatory frameworks that define the functions of the health sciences and related professions, based on the needs of their model of care (8).

The Strategic Direction for Nursing in the Region of the Americas has suggested a study to determine the current state of nursing regulations in the Region (3). The focus of this present study is on registered nurses. Nursing professionals can be categorized as registered nurses, technologists, technicians, and assistants. Registered nurses have 4 to 5 years of higher education. Technologists have secondary education followed by 3 years of vocational or technical training. Technicians have secondary education followed by 18 months to 3 years of technical education. Assistants have primary education followed by 12 to 18 months of formal training (3).

The objectives of this study are to describe and analyze the current nursing regulations across countries in the Region.

\section{METHODS}

A descriptive exploratory study was carried out in which publicly available information regarding nursing regulations was collected from the ministries of health, nursing schools, councils, associations, and boards in 2018. Materials obtained were in Spanish, Portuguese, French, and English. Data was collected to identify the current regulatory bodies and nursing practice requirements in all the countries of the Region. Government chief nursing officers served as key informants on the nursing regulation practices for their respective country.

The main categories analyzed were regulatory bodies, requirements for initial nursing professional registration, and renewal per country. The requirements for initial professional registration were: a) personal information such as national identification, provision of military service (for men), proof of residence, birth certificate, declaration of good physical and mental condition, social security number and personal references; b) academic information; c) payment fees; d) judicial information such as criminal background checks and fingerprinting; e) competency exams; f) jurisprudence exams; g) complementary courses; and h) mandatory social service. The requirements of professional renewal were a) personal information; b) payment of fees; c) proof of continuing education; and e) labor hours. A comparative analysis was conducted to identify similarities and differences across the countries.

Data from the 35 PAHO Member States were organized in the following countries groups: 1. Canada, 2. United States of America, 3. Mexico and Central America, 4. South America, and 5. the Caribbean. Canada and the United States of America were analyzed separately since each state, province, or territory have their own regulations for health professionals.

\section{RESULTS}

All countries regulate the nursing profession through a regulatory body. The International Council of Nurses (ICN) describes four regulatory models: 1) ministry of health model, 2) state led model arm's length body model, 3) professionally led model, and 4) professionally established model (9). In the ministry of health model, the regulatory body is directly controlled by the government through the ministry of health. This is the model used in some Central and South American countries. In the state led model arm's length body model, the regulatory body is appointed by the ministry of health and given the authority to advise on matters related to nursing. This is the model used to regulate nursing professionals in the Caribbean. In the professionally led model, the regulatory body operates on a regional level in which authority is given to the body through the state, provincial, or territorial legislation. The body can govern and enforce standards related to nursing practice. This is the model used in Brazil, Canada and the United States. Professionally established models operate on complete self-regulation without any governmental oversight. Professionally established models are rare in nursing and do not exist in the Region. The most common type of regulatory model in this Region is the state led 
model arm's length body model (20 countries), followed by the ministry of health model (12 countries) and finally the professionally led model (3 countries).

In most Latin American countries, the ministry of health is the regulatory authority and in the English speaking Caribbean countries nursing councils are appointed by the Minister of Health to regulate nurses. In Brazil, Canada and the United States regulatory bodies are responsible for nursing regulation in state, provincial, or territorial level. Table 1 lists the regulatory models by country.

All countries have national legislation to regulate the nursing profession. National legislation (e.g., Nursing Act, Regulatory Decree) describes its executive authority, the purpose and roles of committee/councils if applicable, outlines the registration process, standards, fitness to practice, appeals, mutual recognition agreements, and offenses (10).

In general, all countries require personal and academic information, and payment of fees for initial registration. Judicial information, competency exams, jurisprudence exams, complementary courses, and obligatory social service are required in some of the countries. Judicial information such as criminal background checks and fingerprinting is required in Belize, Canada (except in British Columbia and Quebec), Costa Rica, Dominican Republic, Paraguay, Saint Lucia and the United States (except in Alabama, Alaska and Connecticut).

Competency exams measure the competencies needed to perform safely and effectively as a newly registered nurse (11). It is required for professional registration in the United States, Canada, and Caribbean countries except for the Dominican Republic and Suriname. In the United States, the National Council of State Boards of Nursing (NCSBN), an independent not-for-profit organization, develops a nationwide examination (NCLEX-RN) for registration/licensure. Since 2015, the NCSBN has also been responsible for developing the NCLEX-RN entryto-practice exam for Canada (12). In the English Caribbean countries, the Regional Examination for Nurse Registration (RENR) is managed by the Barbados-based Caribbean Examination Council (CXC) (13).

Jurisprudence exams evaluate an applicant's knowledge of the nursing laws and scope of practice. In Canada they are required in the provinces of British Columbia, Alberta, Ontario and Nova Scotia. In the United States they are required only in Kentucky and Texas.

Complementary courses are additional courses required by the United States' State Board of Nursing to deepen the applicants understanding on a specific topic to influence practice. Courses include topics in ethics, HIV, recognition and reporting of abuse in children, and infection control. They are only required in Massachusetts, Michigan, New York, Oregon, Pennsylvania, and Virginia.

Mandatory social service is a social service commitment required for recent graduates prior to gaining their license to practice. It is a method to attract health workers to rural and underserved populations for one year with stipulations on remuneration scales according to the territory conditions (1416). Obligatory social service for nurses is required in Colombia, Costa Rica, Ecuador, Honduras, and Nicaragua.

Data regarding professional registration renewal also present heterogeneity. The analysis revealed that $43 \%$ of the countries in the Region do not require registration renewal, including Bolivia, Colombia, Cuba, Dominican Republic, Ecuador, El

TABLE 1. Regulatory models by country, Region of the Americas, 2020

\section{Regulatory model}

Ministry of health model

State led model arm's length body model

Professionally led model

\section{Countries}

Argentina, Bolivia, Chile, Cuba, Dominican Republic, Ecuador, El Salvador, Haiti, Nicaragua, Paraguay, Suriname, Uruguay

Antigua and Barbuda, Bahamas, Barbados, Belize, Colombia, Costa Rica, Dominica, Grenada, Guatemala, Guyana, Honduras, Jamaica, Mexico, Panama, Peru, Saint Kitts and Nevis, Saint Lucia, Saint Vincent and the Grenadines, Trinidad and Tobago, Venezuela

Brazil, Canada, United States of America

Salvador, Guatemala, Haiti, Mexico, Nicaragua, Panama, Peru, Suriname, Uruguay and Venezuela. Chile requires registration renewal for the professionals who move to another region or city. The remainder $54.3 \%$ of countries require registration renewal.

All countries that require professional renewal also request payment and academic information from the applicant. The English Caribbean countries require renewal annually (Bahamas, Guyana, Saint Kitts and Nevis, Saint Lucia, Saint Vincent and the Grenadines, Trinidad and Tobago) or biennially (Antigua and Barbuda, Barbados, Dominica, Jamaica); Grenada requires triennial renewal. All Canadian provinces/territories require annual renewal. The United States requires renewal every 1-5 years depending on the state, with most states $(78 \%)$ requiring biennial renewal. Wisconsin is the only state that requires renewal every 5 years. In Central America, Belize, Costa Rica and Honduras require registration renewal biennially. In South America, Argentina, Brazil and Paraguay require registration renewal every five years.

Another requirement for registration renewal is proof of continuing education and labor hours. Continuing education hours are activities that are designed to inform, train, and encourage professional development (17). Continuing education includes a variety of activities such as coursework, training, participation in professional organizations, conference attendance, research, presentations, seminars, etc., that are often measured in hours. In the English Caribbean countries, continuing education hours are required for nurses in Antigua and Barbuda, Barbados, Dominica, Grenada, Jamaica, St Kitts and Nevis, Saint Lucia, and Suriname. Antigua and Barbuda, Jamaica, St Kitts and Nevis, and Saint Lucia require 30 hours of continuing education per renewal period. Grenada requires 60 hours of continuing education for nurses. Suriname requires 100 hours of training that is documented in a "training passport" and is reviewed every 3 years. Barbados and Dominica do require continuing education hours; however, the number of hours are not specified.

Canada has a Continuing Competence Program (CCP) for registered nurses renewing their registration. The CCP is a regulatory program that requires nurses to identify their learning needs, explore their accountability as self-regulated professionals, and develop a learning plan to facilitate their ongoing continuing competence (18). It requires nurses to reflect on their practice annually through a self-assessment, develop a learning plan based on identified learning objectives, and evaluate the impact of learning plans on practice (19). These programs 
exist in all provinces/territories except Quebec, which requires 20 hours of continuing education every year.

Continuing education hours are required in most of the states of the United States, except Arizona, Colorado, Connecticut, Indiana, Maine, Maryland, Mississippi, Missouri, New York, South Dakota, Vermont, and Wisconsin. The number of hours varies among states and ranges between 5-30 hours per renewal cycle. Alaska, Delaware, Florida, Kentucky, Michigan, Nebraska, Oregon and Texas have specific requirements regarding the content of the continuing education hours, such as pain management, substance abuse, domestic violence, ethics and laws.

Labor hours are the number of required clinical practice hours. The required number of hours may vary or may not be required if the applicant's primary employment is not in a clinical setting. Labor hours are required in 16 states of the United States, including Alaska, Arizona, Delaware, Georgia, Idaho, Louisiana, Nebraska, New Hampshire, North Carolina, North Dakota, Oklahoma, Oregon, South Dakota, Utah, Washington, and Wyoming and in all provinces/territories of Canada, except Quebec. In Canada, nurses are required to have 1125 hours of clinical practice every 5 years. In the United States, labor hours range between 100-960 hours per renewal cycle.

The supplementary material includes additional information on each country regulatory body, nursing legislation, competency exams and requirements for registration renewal.

\section{DISCUSSION}

The fundamental purpose of nursing regulation is to ensure that safe nursing care is provided to the public. The initial review of credentials during registration, the periodic professional registration renewal, competency exams, and continuing education serve as mechanisms to safeguard the public.

The results of this study reveal striking differences in the professional registration and requirements in the Region of the Americas. In countries like Canada, United States, and some countries in the English Caribbean countries, requirements for nursing registration and renewal include competency examinations and continuing education.

Competency exams test an applicant's knowledge, skills, and critical thinking needed for entry to practice ensuring safe delivery of care. Although education and training vary in each country, competency exams provide a baseline assessment of a candidate's ability. Competency exams were introduced in the Caribbean in 1990 with the aims to standardize and improve nursing education and facilitate movement of registered nurses among countries in the Caribbean (20). However, there has been persistent concerns regarding the pass rates. For example, in 2013 in Guyana 80\% of the nursing candidates did not pass the Regional Examination for Nursing Registration (RENR). From 2000-2015 the RENR passing rate in Belize was approximately $41 \%$. Unsatisfactory exam scores have prompted the Regional Nursing Board (RNB) to review the exam process and provide remedial instructions after the first failure. The committee has agreed that an applicant has four chances within five years to take the exam. In 2018, with the support of PAHO, the RNB developed its Strategic Plan 2018-2023 based on three strategic priorities: nursing and midwifery education, practice, and leadership to provide solutions to the challenges related to nursing and midwifery (21). The competency exams and pass rates serve as quantitative data measurements that assist in evaluating nursing curriculum, highlight areas of improvement, and assess the applicants' preparedness. This is valuable information that could be used to guide quality improvement strategies in nursing education.

A study (22) examined the relationship between internationally educated nurses' performance competency assessment process and eligibility for nursing registration in Canada. Following a substantially equivalent competency assessment, $67.8 \%$ of internationally educated nurses were referred to bridging education, after which $28 \%$ obtained official $\mathrm{RN}$ registration, while $31 \%$ were ineligible for registration and the remainder were granted temporary registration. In general, applicants who were educated in countries with similar nursing scope of practice and regulation standards had higher scores in the competency exams (22).

The United States National Council Licensure Examination (NCLEX) results from NCSBN reveal similar results regarding the relationship between internationally educated nurses and first time NCLEX pass rates for the United States and Canada. Statistics from January to March 2019, showed that $47.6 \%$ of internationally educated nurses passed the NCLEX the first time compared to $89.9 \%$ first time pass rates for United States-educated nurses (23).

Continuing education is a lifelong process of training, updating knowledge, and skills to advance professional competence and enhance nursing practice (24). Continuing education should be mandated and monitored by regulatory bodies in order to protect the public by ensuring that nurses maintain up to date knowledge, skills, and abilities (25).

Studies have shown the importance of continuing education and training in nursing staff, which are reflected in better organizational climate, improved retention, and improved patient outcomes $(26,27)$. The participation in ongoing training promotes the acquisition of new knowledge and skills among professionals and keeps them informed of new trends, which will ultimately impact their practice and patient safety. The use of technology to promote continuing education has been effective in resource constricted settings in which access to nurse educators and training is limited. For example, a study by Louis and Moloney in 2018 showed the effectiveness of technology to facilitate continuing education among nurses in Haiti. Pre- and post-testing on average showed a $40 \%$ increase in knowledge when nurses were given access to current nursing literature and clinical decision support systems through iPads (28).

Despite the positive impact of continuing education, continuing education hours are not required in many countries such as Argentina, Bahamas, Barbados, Bolivia, Brazil, Chile, Colombia, Costa Rica, Cuba, Dominican Republic, Ecuador, El Salvador, Guatemala, Guyana, Haiti, Honduras, Mexico, Nicaragua, Panama, Paraguay, Peru, Saint Vincent and the Grenadines, Trinidad and Tobago, Uruguay and Venezuela.

Continuing education not only offers a chance to assess ongoing competence; it's an opportunity to provide training and prepare nurses for advanced roles. The results of this study suggest that increased investments should be made to develop, require, and enhance national continuing education programs in the Region.

Nursing regulations can also protect the public from poor quality of care. The Lancet Global Health Commission in High Quality Health Systems informed that poor quality care has been linked to increased health expenditure in the form of medication errors, prolonged hospital stays and readmission, surgical complications, and poor health outcomes $(29,30)$. Poor 
quality care accounts for $60 \%$ of health care related deaths and is responsible for 8 million deaths per year in low and middleincome countries (29).

The Lancet Global Health Commission endorsed four universal actions to raise quality standards across the health system. Two of them were directly related to regulations and the health workforce. The first is to govern for quality by adopting a shared vision of quality care, implementing quality improvement strategies, strong regulation, and continuous learning. The second action is to transform the health workforce by adopting competency based clinical education, encouraging ethical and compassionate health care delivery, and providing adequate resources and supportive environments to healthcare workers (29).

In addition to protecting the public, regulations should support advanced practice nursing roles and enact legislation that defines their scope of practice. Nurses make up the largest health workforce and can play an important role through measures such as skill mix and advancing the scope of practice. A strong nursing regulation outlines clear mechanisms that support these strategies. In the Region of the Americas, expanding the role of nurses in the first level of care can be an important step to guarantee access to health professionals and help countries achieve the goals of universal health and the Sustainable Development Goals.

In 2018, PAHO moved forward in introducing the role of advanced practice nurses (APN) in the first level of care as a response to growing health needs, fill gaps in the availability of highly trained, and well distributed human resources for health. APNs are well established and regulated in the United States and Canada but not in many other countries, although nurses have unofficially adopted advanced roles in setting in which physicians are unavailable. In the Region of the Americas, several countries have started to explore opportunities for APNs. Despite these efforts, many countries in the Region lack the regulatory framework necessary to effectively implement advanced nursing roles (31). Successful implementation of APNs can only come into fruition through intersectional coordination between the regulatory bodies and health and education sectors.

Interventions in other regions can serve as lessons of successful coordination between the regulatory bodies and health and education sectors. The African Health Profession Regulatory Collaborative (ARC) showed how interventions can target nursing regulations to promote nursing practice. The ARC was a four-year initiative involving 17 countries with the goal of strengthening nursing regulations to ensure safe, sustainable, and managed HIV/AIDS treatment (32). The objectives included scaling up HIV/AIDS services through strengthened regulatory frameworks, align regulatory functions with global guidelines and regional standards (registration, accreditation, continuing education, scope of practice, professional conduct and discipline), and foster a sustained regional network of regulatory leaders to exchange knowledge and best practices (32). They provided the countries with regulatory resources such as the Continuing Professional Development Toolkit, grants, technical assistance, and held regional meetings (33). This initiative was able to strengthen nursing regulations, especially addressing continuing professional development and scopes of practice. As a result, there were significant increases in leadership and organizational capacity (34). The success of the ARC shows promise that targeted interventions could be used to improve not just nursing regulations and advanced nursing roles but also the regulation of all health professionals.

This study had some limitations, including incomplete and/ or out of date information on regulatory databases. It was also difficult to assess the extent of adherence to regulatory guidelines and requirements by the countries.

PAHO recommends that nursing regulations be tailored to meet country specific health needs. The Strategic Direction for Nursing in the Region of the Americas urges countries to assess and update current status of nursing regulations (3). Countries should then implement and monitor processes to ensure compliance with regulatory agencies (3). The results of this study highlight the need for countries to evaluate competency and training, consider the use of competency exams for initial registration, and encourage continuing education as requirements for registration renewal. These measures will help foster positive practices and ensure that capable and well-trained nurses deliver quality care. This study provides an overview of the current nursing regulations in the Region of the Americas and highlights areas that can be improved. These results may be used to guide interventions and inform regulation policy efforts. Regulations provide an adequate system of continuous assessment of health professionals, enforce policies that promote quality and patient safety, encourage education institutions to innovate and change, define scopes of practice and protect professional integrity. Additionally, improved regulations offer the opportunity to develop legislation that supports the implementation of advanced practice nurses. Both factors are important in the pursuit of universal health access and coverage and the achievement of the Sustainable Development Goals.

Author contributions. All authors contributed to the collection of information, analysis, and interpretation. All authors reviewed and approved the final version.

\section{Conflicts of interests. None declared.}

Disclaimer. Authors hold sole responsibility for the views expressed in the manuscript, which may not necessarily reflect the opinion or policy of the RPSP/PAJPH and/or PAHO.

\section{REFERENCES}

1. Pan American Health Organization. Strategy on Human Resources for Universal Access to Health and Universal Health Coverage. Washington, D.C.: PAHO, 2017.

2. Squires A, Dorsen C. Qualitative Research in Nursing and Health Professions Regulation. J Nurs Regul. 2018;9(3):15-26.
3. Pan American Health Organization. Strategic Directions for Nursing in the Region of the Americas. Washington, D.C.: PAHO; 2019.

4. Organización Panamericana de la Salud. Área de Fortalecimiento de Sistemas de Salud. Unidad de Recursos Humanos para la Salud. 
Regulación de la Enfermería en América Latina. Washington, DC: PAHO; 2011.

5. World Health Organization. WHO global strategy on peoplecentred and integrated health services: interim report. Geneva: World Health Organization; 2015

6. World Health Organization. Global strategy on human resources for health: workforce 2030. Available from: https:/ /www.who.int/ hrh/resources/globstrathrh-2030/en/

7. World Health Organization. Global strategic directions for strengthening nursing and midwifery 2016-2020. Available from: https://www.who.int/hrh/nursing_midwifery/global-strategicmidwifery2016-2020.pdf?ua=1

8. Pan American Health Organization. Plan of action on human resources for universal access to health and universal health coverage 2018-2023. Washington, D.C.: PAHO; 2018.

9. Benton DC, Morrison A. Regulation 2020: Exploration of the present; vision for the future. Geneva: ICN; 2009

10. Benton DC, Model Nursing Act Toolkit. Geneva: ICN; 2007.

11. National Council of State Boards of Nursing. NCLEX-RN examination: Test plan for the national council licensure examination for registered nurses. Chicago: NCSBN; 2018.

12. National Council of State Boards of Nursing. 2017 NCLEX® Examination Statistics. Chicago: NCSBN; 2018.

13. Caribbean Community (CARICOM). Preparation Guide [for] Regional Examination for Nurse Registration [for] CARICOM Countries. St Michael, Barbados: Caribbean Community (CARICOM), 2014.

14. Carpio C, Santiago Bench N. The Health Workforce in Latin America and the Caribbean: An Analysis of Colombia, Costa Rica, Jamaica, Panama, Peru, and Uruguay. The World Bank; 2015 Jun 25.

15. Frehywot S, Mullan F, Payne PW, Ross H. Compulsory service programmes for recruiting health workers in remote and rural areas: do they work?. Bull World Health Organ. 2010;88:364-70.

16. Sancho Ugalde H, Mata Roldán S. Perspectivas del servicio médico social en Costa Rica. AMC. 2000;42(2):71-5.

17. Agyepong EB, Okyere ED. Analysis of the Concept Continuing Education in Nursing Education. JoEED. 2018;5(1):96-107.

18. Nova Scotia College of Nursing . Continuing Competence Program (CCP) 2019. Available from: https://crnns.ca/registration/ ccp/.

19. Campbell B, Mackay G. Continuing competence: An Ontario nursing regulatory program that supports nurses and employers. Nurs Adm Q. 2001;25(2):22-30.

20. Reid UV. Regional Examination for Nurse Registration, Commonwealth Caribbean. Int Nurs Rev. 2000;47(3):174-83.

21. Regional nurses agree to review of exams managed by CXC. Jamaica Observer. 2018 August 14, 2018. Available from: http:// www.jamaicaobserver.com/latestnews/Regional_nurses_agree_ to_review_of_exams_managed_by_CXC?profile $=1228$
22. Nordstrom PM, Kwan JA, Wang M, Qiu Z, Cummings GG, Giblin C. Internationally educated nurses' competency assessment and registration outcomes. Int J Migr Health Soc Care. 2018;14(3):332-46.

23. National Council of State Boards of Nursing. 2019 Number of Candidates Taking NCLEX Examination and Percent Passing, by Type of Candidate. Chicago: NCSBN; 2018.

24. Gallagher L. Continuing education in nursing: a concept analysis. Nurse Educ Today. 2007;27(5):466-73.

25. Iliffe J. Developing a national continuing professional development framework. Afr J Midwifery Womens Health. 2011;5(4):189-94.

26. Aiken LH, Cimiotti JP, Sloane DM, Smith HL, Flynn L, Neff DF. The effects of nurse staffing and nurse education on patient deaths in hospitals with different nurse work environments. Medical care. 2011;49(12):1047.

27. Marzuki MA, Hassan H, Wichaikhum O, Nantsupawat R. Continuing nursing education: best practice initiative in nursing practice environment. Procedia Soc Behav Sci. 2012;60:450-5.

28. Louis KR, Moloney B. Addressing Health Disparities in Haiti through Nursing Education and Technology. Int J Nurs Clin Pract. 2018;5.

29. Kruk ME GA, Arsenault C, Jordan K, Leslie HH, Roder-DeWan S, Adeyi O, Barker P, Daelmans B, Doubova SV, English M. High-quality health systems in the Sustainable Development Goals era: time for a revolution. The Lancet Global Health Commission on High Quality Health Systems in the SDG Era. 2018 November:e1196-e252.

30. Kieny MP, Evans TG, Scarpetta S, Kelley E, Klazinga N, Forde I, Veillard J, Leatherman S, Syed S, Kim SM. Delivering quality health services: a global imperative for universal health coverage. Washington, DC: World Bank Group; 2018.

31. Pan American Health Organization. Expanding the Roles of Nurses in Primary Health Care. Washington, D.C.: PAHO; 2018.

32. Gross JM, Maureen K, Carey M. A model for advancing professional nursing regulation: The African Health Profession Regulatory Collaborative. J Nurs Regul. 2015;6(3):29-33.

33. African Health Profession Regulatory Collaborative. Continuing professional development for nurses and midwives: a toolkit for developing a national CPD framework. ARC; 2013.

34. Gross JM, McCarthy CF, Verani AR, Iliffe J, Kelley MA, Hepburn $\mathrm{KW}$, et al. Evaluation of the impact of the ARC program on national nursing and midwifery regulations, leadership, and organizational capacity in East, Central, and Southern Africa. BMC Health Serv Res. 2018;18(1):406.

Manuscript received on 13 September 2019. Revised version accepted for publication on 26 June 2020. 


\section{Regulación de la práctica de la enfermería en la Región de las Américas}

RESUMEN Objetivo. Describir y analizar la normativa reguladora vigente en materia de enfermería en los países de la Región de las Américas.

Métodos. Se efectuó un análisis comparativo de los países reuniendo información de los ministerios de salud, escuelas de enfermería, consejos, asociaciones y comités profesionales en 2018. Las principales categorías evaluadas fueron los tipos de organismos reguladores, los requisitos para el registro profesional inicial y la renovación del registro.

Resultados. Todos los países regulan la profesión de enfermería por medio de un organismo regulatorio. Los Estados Unidos, Canadá y la mayoría de los países del Caribe exigen exámenes de competencia para el registro inicial. En el 54,3\% de los países se exige la renovación periódica del registro. En los Estados Unidos, Canadá y el 53\% de los países del Caribe se requiere cumplimentar educación continua para renovar el registro profesional. En los Estados Unidos y Canadá se requiere acreditar horas de trabajo.

Conclusión. Los mecanismos regulatorios promueven y protegen la integridad profesional. La Organización Panamericana de la Salud/Organización Mundial de la Salud recomienda que los países evalúen la competencia y la capacitación profesionales, consideren la posibilidad de utilizar exámenes de competencia para el registro inicial y requieran educación continua como requisito para renovar el registro profesional.

Palabras clave Fuerza laboral en salud; enfermería en salud comunitaria; legislación como asunto; educación continua en enfermería; rol de la enfermera; Américas. 